$\xi=-1$

\title{
Modeling And Prediction of Mechanical Strength in Electron Beam Welded Dissimilar Metal Joints of Stainless Steel 304 and Copper Using Grey Relation Analysis
}

\author{
R. Ajith Raj ${ }^{1 *}$, M. Dev Anand ${ }^{2}$ \\ ${ }^{1}$ Head, Department Of Aeronautical Engineering, Noorul Islam Centre For Higher Education, Kumaracoil, Kanyakumari District, Tamil \\ Nadu, India. \\ ${ }^{2}$ Director Research, Department Of Mechanical Engineering, Noorul Islam Centre For Higher Education, Kumaracoil, Kanyakumari \\ District, Tamil Nadu, India. \\ *Corresponding Author E-Mail:Ajithraj006@Gmail.Com
}

\begin{abstract}
Aircraft industries witness an extensive variety of utilizations in unique welded joints thinking about the benefit of quality and high corrosion protection. In any case, joining of dissimilar materials is more mind boggling because of the distinction in material properties. In this investigation dissimilar metal joints of pure Copper plates and Stainless Steel 304 plates of $3 \mathrm{~mm}$ thickness were welded with Electron Beam Welding. The welding input parameters like Welding speed, Beam current and Work distance liable to quality of weld are considered. Plan of analysis has been made utilizing Taguchi strategy with three levels of input values. Ultimate tensile strength and hardness number were found to decide the mechanical quality. Both the yield esteems are consolidated for expectation and optimized using Gray Relation Analysis (GRA). The impacts of the input parameters towards weld quality were analyzed using ANOVA.
\end{abstract}

Keywords: Dissimilar metal joints, electron beam welding, mechanical strength, grey relation analysis.

\section{Introduction}

The use of Electron beam for dissimilar metal joints in aircraft industry has amplified in the present days due to its fastest rate constricted with the quality standards. In electron beam welding the fusion zone and the heat affected zone are very narrow when compared with other conventional welding methods. The heat energy produced is a function of beam current, beam Voltage, welding time and Work distance. Taguchi method was adopted in this research and nine sets of input values of beam current, welding speed and Work distance were considered. Grey Relation Analysis has been carried out for the Prediction of Mechanical strength in Electron Beam Welded dissimilar metal joints of Stainless Steel 304 and Copper.

\section{Literature Review}

Welding is a procedure with various troublesome normal wonders, the greater part of which can't be completely comprehended. It isn't conceivable to build up a differential condition of some confused procedure. In such circumstances, models are produced using the tests and afterward examined by relapse techniques and yield can be anticipated. Yang et al., [1] performed grey relation examination for submerged arc welding process. Their outcomes demonstrate a few deviations in expectation at the middle of the road focuses. To beat this issue, Ganjigatti et al., [2] built up another approach to demonstrate the input yield connections via doing regression investigation. A neural system of model with back propagation was utilized by Nagesh and Datta. [3] Using this they have anticipated the spot geometries of the steel and iron plates. De et al., [4] used an ANN strategy to anticipate the welding impacts of Gas Metal Arc Welding technique. Kim et al., [5] displayed that neural structure based model gives the best results than the precisely influenced conditions can settle. This perception was affirmed by Lee and Um [6] with his exploration in neural system and inferred that this strategy will give great outcomes when compared with other existing models.

Tay and Butler [7] utilized a spiral premise capacity to surmised non-direct flow of the welding procedure to improve the essential welding parameters. Benyounis et al., [8] developed Response Surface Methodology (RSM) to anticipate weld geometries in medium carbon steel welded by laser welding. Gunaraj and Murugan [9] accomplished experiments using submerged arc welding for funnels made of stainless steel in light of CCD with four elements, at five levels to anticipate dab geometry parameters.

Taguchi [10] created technique for directing analyses in light of orthogonal beam, which gave a much diminished change to try different things with ideal setting of control parameters responsible to produce quality welds. This strategy demonstrated the plan of examinations with advancement of control parameters to acquire the best outcomes. Taguchi strategy was adjusted by Tarng and Yang [11] to examine the impact of each welding procedure parameter on the weld-globule geometry. Tarng et al., [12] utilized Gray social examination to research numerous execution attributes in the Taguchi technique for the advancement of submerged bend welding process. By utilizing this approach they enormously improve the advancement technique for deciding the ideal welding parameters with different execution qualities in the submerged bend welding process. R. Ajith Raj et al., [8] 
anticipated the mechanical quality of TIG welded Stainless steel 304 utilizing Gray RSM. Mechanical properties like UTS and hardness number were considered as output values in this research and joined through Gray Relation Analysis (GRA) and anticipated the review utilizing Response Surface Methodology (RSM). G. Metzger et al. [14] contemplated the weld ability of different metal joints with metallographic examination and elastic tests in the welded example. R. Rai et al., [15] built up a numerical model for 3Dheat exchange and liquid stream in electron beam welding for 304L stainless steel. In this exploration welds made at various power densities. MiroslavSahul et al. [16] considered dissimilar metal joints of Copper and Stainless Steel plates with laser welding. K. Kanaujia et al., [17] enhanced the elasticity of AISI304 Stainless Steel and Copper utilizing Laser Welding. Info welding parameters, for example, laser control, welding speed and welding length were considered in this investigation. Taguchi approach was utilized for the plan of investigations and the Joint quality was resolved utilizing the universal testing machine. T.A. Mai and A.C. Spowage [18] dissected the dissimilar joints of copper/steel plates, steel/kovar plates, and copper/aluminum plates utilizing laser welding. Rakesh Chaudhari et al., [19] made research to locate the distinctive strategies to join different metals and inferred that MIG does not agree copper to liquefy with press, which prompts absence of entrance. P. Lacki et al., [20] examined the thermo-mechanical examination of In conel 706 tube utilizing electron beam welding.

\section{Experimentation}

Stainless Steel 304 and Copper both of size 100mm X 60mm X $6 \mathrm{~mm}$ has been taken for this research. A design of experiment for the three input parameters with three levels of value is made by adopting Taguchi method. To analyze the weld quality mechanical testing has been carried out to find the Ultimate Tensile strength and Micro hardness using UTM and Vickers Hardness. The different process parameters and obtained output values are tabulated in Table 1.

Table 1: Input and Output Parameters of EBW Welding

\begin{tabular}{|c|c|c|c|c|c|}
\hline \multirow{2}{*}{$\begin{array}{c}\text { Sample } \\
\text { Number }\end{array}$} & \multicolumn{3}{|c|}{ Input Values } & \multicolumn{2}{c|}{ Output Values } \\
\cline { 2 - 6 } & $\begin{array}{c}\text { Beam } \\
\text { Current } \\
\text { mA }\end{array}$ & $\begin{array}{c}\text { Welding } \\
\text { Speed } \\
\text { mm/s }\end{array}$ & $\begin{array}{c}\text { Work } \\
\text { Distance } \\
\text { mm }\end{array}$ & $\begin{array}{c}\text { Tensile } \\
\text { Strength } \\
\text { Mpa }\end{array}$ & $\begin{array}{c}\text { Hardness } \\
\text { Number } \\
\text { HV }\end{array}$ \\
\hline 1 & 10 & 8 & 100 & 34.92 & 108 \\
\hline 2 & 10 & 24 & 260 & 32.01 & 102 \\
\hline 3 & 10 & 40 & 425 & 29.10 & 98 \\
\hline 4 & 30 & 8 & 260 & 280.24 & 182 \\
\hline 5 & 30 & 24 & 425 & 90.22 & 114 \\
\hline 6 & 30 & 40 & 100 & 81.49 & 143 \\
\hline 7 & 50 & 8 & 425 & 262.01 & 162 \\
\hline 8 & 50 & 24 & 100 & 219.24 & 146 \\
\hline 9 & 50 & 40 & 260 & 242.75 & 150 \\
\hline
\end{tabular}

\section{Grey relation Analysis}

In Grey Relation examination both the output parameters were changed over in to a solitary Grey relation grade. Utilizing this response grade prediction and optimization has been completed. The different advances took after to determine the grey relation grade has been portrayed beneath.

\section{Normalization}

The first step in grey relation analysis is the normalization or pre processing of the two output data. Here the values of tensile strength and hardness number have been normalized. The formula used for this purpose is given below.

$$
\mathrm{Y}_{\mathrm{i}}=\frac{(\mathrm{Xi}-\mathrm{Xi} \text { Minimum })}{(\mathrm{Xi} \text { Maximum-Xi Minimum })}
$$

Where

$Y_{i}$ - Normalized value

$\mathrm{X}_{\mathrm{i}}$ - Output values

$\mathrm{i}=1,2,3,4, \ldots \mathrm{n}$.

The normalized values of tensile strength and Hardness number are tabulated in Table 2.

Table 2: Normalized Output Values of EBW Welding

\begin{tabular}{|c|c|c|c|c|c|}
\hline \multirow{2}{*}{$\begin{array}{c}\text { Sample } \\
\text { Number }\end{array}$} & $\begin{array}{c}|c| \\
\text { Bnput Values } \\
\text { Current } \\
\mathbf{~ m A ~}\end{array}$ & $\begin{array}{c}\text { Welding } \\
\text { Speed } \\
\mathbf{m m} / \mathbf{s}\end{array}$ & $\begin{array}{c}\text { Work } \\
\text { Distance } \\
\mathbf{m m}\end{array}$ & $\begin{array}{c}\text { Normalized } \\
\text { Tensile } \\
\text { Strength } \\
\text { Mpa }\end{array}$ & $\begin{array}{c}\text { Normalized } \\
\text { Hardness } \\
\text { Number } \\
\text { HV }\end{array}$ \\
\hline 1 & 10 & 8 & 100 & 0.023174 & 0.119048 \\
\hline 2 & 10 & 24 & 260 & 0.011587 & 0.047619 \\
\hline 3 & 10 & 40 & 425 & 0 & 0 \\
\hline 4 & 30 & 8 & 260 & 1 & 1 \\
\hline 5 & 30 & 24 & 425 & 0.24337 & 0.190476 \\
\hline 6 & 30 & 40 & 100 & 0.208609 & 0.535714 \\
\hline 7 & 50 & 8 & 425 & 0.927411 & 0.761905 \\
\hline 8 & 50 & 24 & 100 & 0.757108 & 0.571429 \\
\hline 9 & 50 & 40 & 260 & 0.850721 & 0.619048 \\
\hline
\end{tabular}

\section{Grey Relation Coefficient}

The next step in this process is to find the coefficient value of the normalized responses. The formula used to find the coefficient value is given below.

$$
\mathrm{C}=\frac{(\text { YiMinimum }+ \text { D YiMaximum })}{(\text { Yi }+ \text { D YiMaximum })}
$$

Where,

$\mathrm{C}$ is the grey relation coefficient

$\mathrm{D}$ is the distinguishing coefficient ranges $(0 \leq \mathrm{D} \leq 1)$

The calculated coefficient values of the normalized responses are tabulated in Table 3.

Table 3: Grey Relation Coefficient Values of Normalized Responses

\begin{tabular}{|l|c|c|c|c|c|}
\hline \multirow{4}{*}{$\begin{array}{c}\text { Sample } \\
\text { Number }\end{array}$} & \multicolumn{3}{|c|}{ Input Values } & \multicolumn{2}{c|}{ Output Values } \\
\cline { 2 - 6 } & $\begin{array}{c}\text { Beam } \\
\text { Current } \\
\mathbf{~ m A ~}\end{array}$ & $\begin{array}{c}\text { Welding } \\
\text { Speed } \\
\mathbf{m m} / \mathbf{s}\end{array}$ & $\begin{array}{c}\text { Work } \\
\text { Distance } \\
\text { mm } \\
\text { Relation } \\
\text { Coefficient } \\
\text { (Tensile } \\
\text { Strength } \\
\text { Mpa) }\end{array}$ & $\begin{array}{c}\text { Grey } \\
\text { Relation } \\
\text { Coefficient } \\
\text { (Hardness } \\
\text { Number } \\
\text { HV) }\end{array}$ \\
\hline 1 & 10 & 8 & 100 & 0.338564 & 0.362069 \\
\hline 2 & 10 & 24 & 260 & 0.335928 & 0.344262 \\
\hline 3 & 10 & 40 & 425 & 0.333333 & 0.333333 \\
\hline 4 & 30 & 8 & 260 & 1 & 1 \\
\hline 5 & 30 & 24 & 425 & 0.39789 & 0.381818 \\
\hline 6 & 30 & 40 & 100 & 0.387179 & 0.518519 \\
\hline 7 & 50 & 8 & 425 & 0.873227 & 0.677419 \\
\hline 8 & 50 & 24 & 100 & 0.673045 & 0.538462 \\
\hline 9 & 50 & 40 & 260 & 0.770085 & 0.567568 \\
\hline
\end{tabular}

\section{Grey Relation Grade}

Grey Relation Grade for the tensile strength and micro hardness has been found out by averaging the grey relation coefficient values. This calculated grade values can be utilized for optimization and prediction of mechanical strength of the welded joint with numerous performance features. The grade values thus found from the grey relation coefficient values are tabulated in Table 4.

Table 4: Grey Relation Grade Values

\begin{tabular}{|c|c|c|c|c|}
\hline $\begin{array}{c}\text { Sample } \\
\text { Number }\end{array}$ & $\begin{array}{c}\text { Beam } \\
\text { Current } \\
\text { mA }\end{array}$ & $\begin{array}{c}\text { Welding } \\
\text { Speed } \\
\text { mm/s } \\
\text { I }\end{array}$ & $\begin{array}{c}\text { Work } \\
\text { Distance } \\
\text { mm } \\
\text { D }\end{array}$ & $\begin{array}{c}\text { Grey } \\
\text { Relation } \\
\text { Grade } \\
\text { GRG }\end{array}$ \\
\hline 1 & 10 & 8 & 100 & 0.350316 \\
\hline 2 & 10 & 24 & 260 & 0.340095 \\
\hline
\end{tabular}




\begin{tabular}{|l|c|c|c|c|}
\hline 3 & 10 & 40 & 425 & 0.333333 \\
\hline 4 & 30 & 8 & 260 & 1 \\
\hline 5 & 30 & 24 & 425 & 0.389854 \\
\hline 6 & 30 & 40 & 100 & 0.452849 \\
\hline 7 & 50 & 8 & 425 & 0.775323 \\
\hline 8 & 50 & 24 & 100 & 0.605753 \\
\hline 9 & 50 & 40 & 260 & 0.668826 \\
\hline
\end{tabular}

The values of grey relation grade have been plotted in a time series plot as shown in Figure 1.

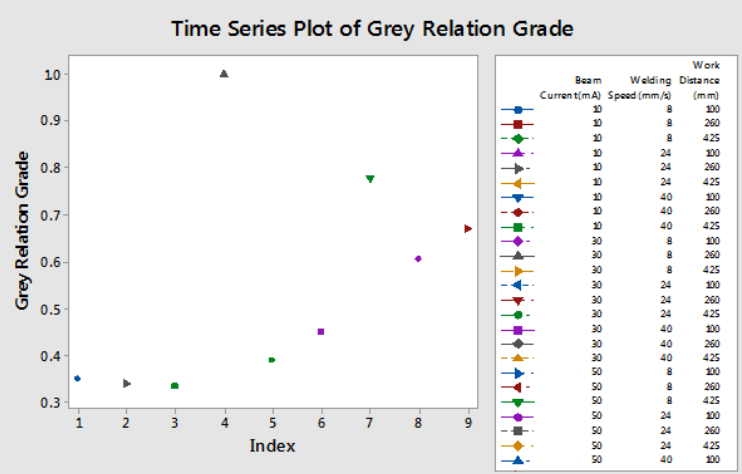

Figure 1: Time series strategy of grey relation grade values

Utilizing the estimations of Gray Relation Grade, fundamental impact plot for current, welding speed and work distance has been made utilizing ANOVA in MINI TAB programming as appeared in figure 2 .

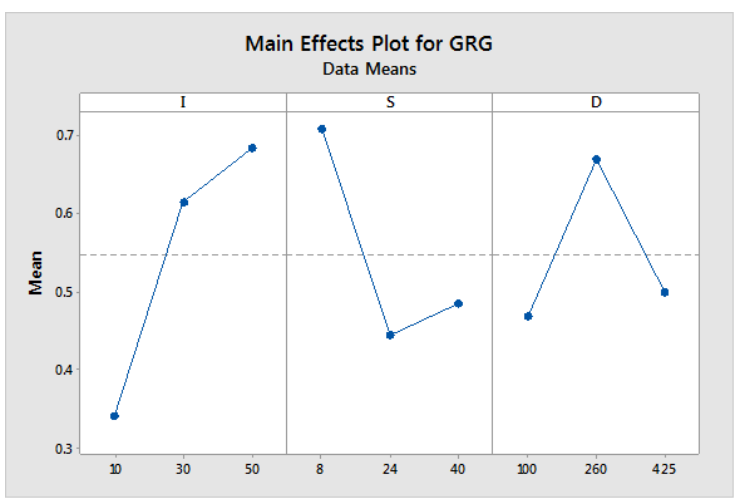

Figure 2: Main effects strategy of grey relation grade values

From the above plot it was found that the optimum input values of beam current, welding speed and Working distance are $50 \mathrm{~mA}, 8$ $\mathrm{mm} / \mathrm{s}$ and $260 \mathrm{~mm}$.

\section{Factor Information}

Factor Type Levels Values

$\begin{array}{llllll}\text { I } & \text { Fixed } & 3 & 10, & 30, & 50 \\ \text { S } & \text { Fixed } & 3 & 8, & 24, & 40 \\ \text { D } & \text { Fixed } & 3 & 100, & 260, & 425\end{array}$

Analysis of Variance

Source DFAdj SS Adj MS F-Value P-Value

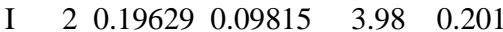

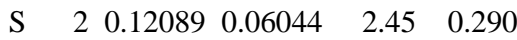

$\begin{array}{llllll}\text { D } & 2 & 0.06984 & 0.03492 & 1.42 & 0.414\end{array}$

Error 20.049320 .02466

Total $8 \quad 0.43634$

Model Summary

$$
\begin{array}{lcc}
\text { S R-sq } & \text { R-sq(adj) } R \text {-sq(pred) } \\
0.157033 & 88.70 \% & 54.79 \% \\
0.00 \% & &
\end{array}
$$

Coefficients

Term CoefSECoef T-Value P-Value VIF

$\begin{array}{lllll}\text { Constant } & 0.5463 & 0.0523 & 10.44 & 0.009\end{array}$

I

$\begin{array}{llllll}10 & -0.2050 & 0.0740 & -2.77 & 0.109 & 1.33\end{array}$

$\begin{array}{llllll}30 & 0.0680 & 0.0740 & 0.92 & 0.455 & 1.33\end{array}$

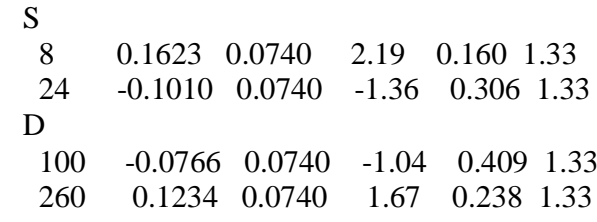

\section{Regression Equation}

$\mathrm{GRG}=0.5463-0.2050$ I_10 +0.0680 I_30 + 0.1370 I_50

$+0.1623 \mathrm{~S} \_8-0.1010 \mathrm{~S} \_24$

- 0.0613 S_40 - 0.0766 D_100 + 0.1234 D_260 - 0.0468 D_425

From the above regression equation the predicted output grade shows that the average error obtained is 0.04932

\section{Influence of Input Parameters Towards Weld Quality}

From the analysis of variance the percentage of influence of the three input parameters towards weld quality are found out. The formula used to find the percentage of influence is given below

$$
\% \text { of Influence }=\frac{\text { Adj SS }}{\text { Total }} \times 100
$$

Using this formula the proportion of effect of all the three welding machine input parameters has been calculated as mentioned in table 5 .

Fable 5: Percentage of Influence of Input Parameters

\begin{tabular}{|c|c|c|c|}
\hline Source & Adj SS & Total & \% of Influence \\
\hline Beam Current & 0.19629 & 0.43634 & 44 \\
\hline Welding Speed & 0.12089 & 0.43634 & 27.7 \\
\hline Work Distance & 0.06984 & 0.43634 & 16 \\
\hline
\end{tabular}

From the above Table 5 it was found that the percentage of error is 11.3 .

The percentage of influence of Beam current, Welding speed and

Work distance is also represented in the bar chart as shown in Figure 3.

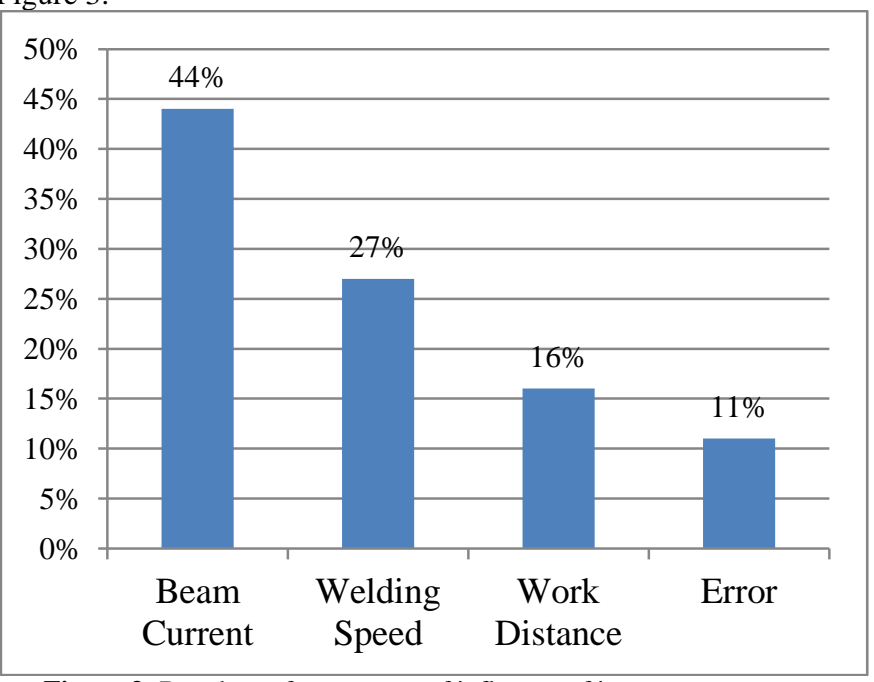

Figure 3: Bar chart of percentage of influence of input parameters

\section{Effect of Current and Speed on Grey Relation Grade}

The estimations of Tensile strength and hardness number were changed over to a solitary goal as grade value. A contour plot has been made for the grade value as an incentive regarding beam current and welding speed as appeared in Figure 4. 


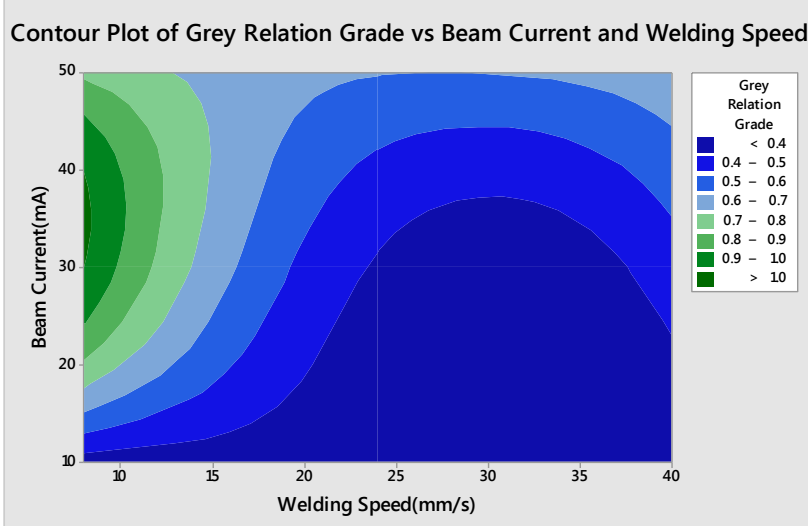

Figure 4: Contour plot of grey relation grade Vs beam current and welding speed

By analysing this contour the impact of these input parameter values on the grade value can be assumed. It was found that the grade value is maximum when the speed is less and Beam current is maximum.

\section{Effect of Beam Current and Work Distance on Grey Relation Grade}

A contour has been created for the grade value with respect to Beam current and work distance as shown in Figure 5.

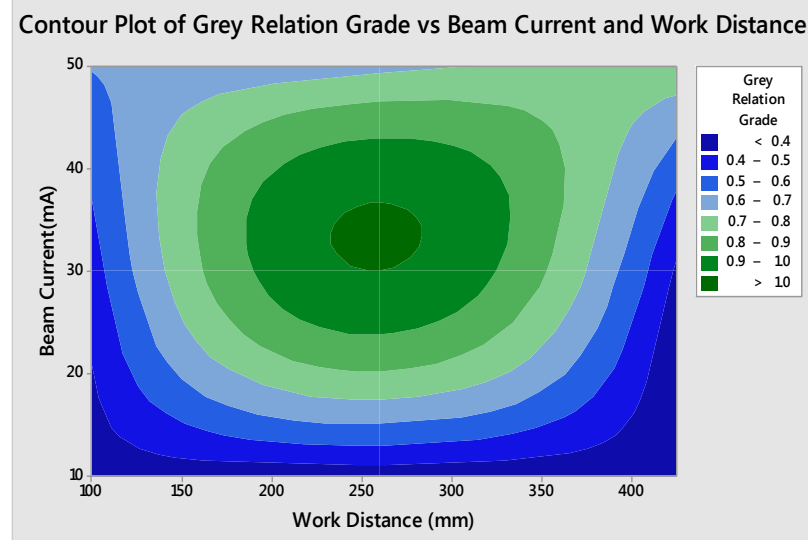

Figure 5: Contour plot of grey relation grade Vs beam current and work distance

By analysing this contour the impact of the input parameter values on the grade value can be assumed. It was found that the grade value is found to be maximum when the Beam current is $30 \mathrm{~mA}$ and work distance is $260 \mathrm{~mm}$.

\section{Effect of Welding Speed and Work Distance on Grey Relation Grade}

A contour has been created for the grade value with respect to welding speed and work distance as shown in Figure 6.

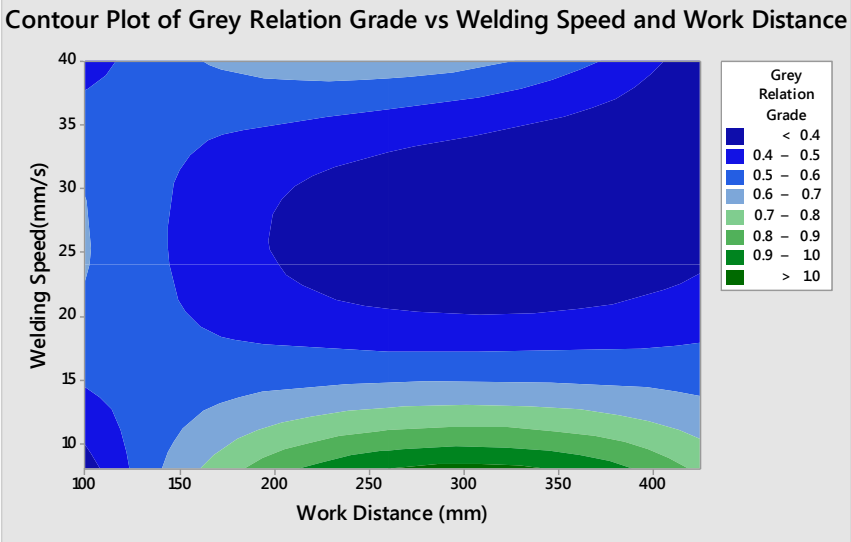

Figure 6: Contour plot of grey relation grade Vs welding speed and work distance

By analysing this contour the impact of the input parameter values on the grade value can be found out. It was found that the grade value is maximum when the welding speed is less and work distance is medium. It was found that the grade value is less when the work distance is too less and if it is too high.

\section{Conclusion}

The values of two output parameters Tensile strength and hardness number were converted to a single objective as grade value for prediction and optimized using Grey Relation Analysis (GRA). The impacts of the input parameters towards weld quality were additionally analyzed. The got result shows that the mistake acquired in the predicted output response grade is 0.04932 .

\section{References}

[1] Yang LJ, Bibby MJ \& Chandel RS, "Linear Regression Equations for Modeling the Submerged-Arc Welding Process", Journal of Material Processing Technology, vol.39, (1993), pp.33-42.

[2] Ganjigatti JP, Pratihar DK \& Roy Choudhury A, "Global Versus Cluster-Wise Regression Analyses for Prediction of Bead geometry in MIG Welding Process", Journal of Material Processing Technology, vol.189, (2007), pp.352-366.

[3] Nagesh DS \& Datta GL, "Prediction of weld Bead Geometry and Penetration in Shielded Metal-Arc Welding Using artificial Neura Networks", Journal of Material Processing Technology, vol.123, (2002), pp.303-312.

[4] De A, Jantre J \& Ghosh PK, "Prediction of Weld Quality in Pulsed Current GMAW Process Using Artificial Neural Network", Science and Technology of Welding and Joining, vol.9, no.3, (2004), pp.253-259.

[5] Kim IS, Son JS, Park CE, Lee CW \& Prasad YKDV, "A Study on Prediction of Bead Height in Robotic Arc Welding Using a Neural Network", Journal of Material Processing Technology, (2002), pp.229-234.

[6] Lee JI \& Um KW, "A Prediction of Welding Parameters by Prediction of back-Bead Geometry", Journal of Material Processing Technology, vol.108, (2000), pp.106-113.

[7] Tay KM \& Butler C, "Modelling and Optimizing of a MIG Welding Process a Case Study Using Experimental Designs and Neural Networks", International Conference on Quality and Reliability Engineering, vol. 13, (1997), pp.61-70.

[8] Benyounis KY, Olabi AG \& Hashmi MSJ, "Effect of Laser Welding parameters on the Heat Input and Weld-Bead Profile", Journal of Material Processing Technology, (2005), pp.978-985.

[9] Gunaraj V \& Murugan N, "Prediction of heat-affected zone characteristics in submerged arc welding of structural steel pipes", Welding Journal-New York, Vol.81, No.3, (2002)

[10] Taguchi G, Introduction to Quality Engineering, Asian Productivity Organization, Tokyo, (1990).

[11] Tarng YS \& Yang WH, "Optimisation of the Weld Bead Geometry in Gas Tungsten Arc Welding by the Taguchi Method", 
International Journal of Advanced Manufacturing Technology, vol.14, (1998), pp.549-554.

[12] Tarng YS, Juang SC \& Chang CH, "The Use of Grey-Based Taguchi Methods to Determine Submerged Arc Welding Process Parameters in Hard-Facing", Journal of Material Processing Technology, vol.128, (2002), pp.1-6.

[13] Ajith Raj R, Rohith IJ \& Dev Anand M, "Mechanical Strength Prediction of TIG Welded Stainless Steel 304 Using Grey RSM", International Journal of Mechanical Engineering and Technology, vol.8, (2017), pp.840-847.

[14] Metzger G \& Lison R, "Electron Beam Welding of Dissimilar Metals", Welding Research Supplement, (1976), pp.230-240.

[15] Rai R, Palmer TA, Elmer JW \& Debroy T, "Heat Transfer and Fluid Flow during Electron Beam Welding of 304L Stainless Steel Alloy", Welding Journal, vol.88, (2009).

[16] Miroslav S, Martin S, Milan T \& Paulina Z, "Disk Laser Welding of Copper to Stainless Steel", Advanced Materials Research vol. 1077, (2015).

[17] Kanaujia KK, Rout MP, Behera BC, Sahoo SK \& Maharana BK, "Optimization of Tensile Strength of AISI304 Stainless Steel and Copper using Nd: YAG Laser Welding", Proc. of the 5th International Conference on Advances in Mechanical Engineering (ICAME), pp.06-08, (2011).

[18] Mai TA \& Spowage AC, "Characterisation of Dissimilar Joints in Laser Welding of Steel-Kovar, Copper-Steel and CopperAluminium”, Materials Science and Engineering, vol.374, (2004), pp.224-233.

[19] Rakesh C, Riddhish P \& Asha I, "Reliability of Dissimilar Metal Joints Using Fusion Welding: A Review", International Conference on Machine Learning, Electrical and Mechanical Engineering, (2014).

[20] Lacki P, Adamus K, Wojsyk K, Zawadzki M \& Nitkiewicz Z, "Modeling of Heat Source Based on Parameters of Electron Beam Welding Process", Archives of Metallurgy and Materials, vol.56, no.2, (2011), pp.455-462. 